\title{
Bicaval/bipulmonary Orthotopic Heart Transplantation
}

Transplante cardíaco ortotópico bicaval/bipulmonar

Jarbas J. DINKHUYSEN ${ }^{1}$

RBCCV 44205-647

\section{Abstract}

The author describes a technique of performing bicaval/ double-lung heart transplantation including the

evaluation, harvesting and conservation of the donated

organ. Additionally, the regime of pre-operative

immunosuppression, the techniques of myocardial

protection, resection of the native heart and implantation

of the donated organ are described.

Descriptors: Heart transplantation, methods.

Transplantation, homologous
Resumo

$O$ autor descreve técnica para realização de transplante cardíaco bicaval-bipulmonar, incluindo avaliação, retirada e conservação do órgão do doador. Além disso, são descritos o esquema de imunossupressão pré-operatória, as técnicas de proteção miocárdica, ressecção do coração nativo e implante do órgão doado.

Descritores: Transplante cardíaco, métodos. Transplante homólogo.

1 - Head of transplantation section of the Instituto Dante Pazzanese de Cardiologia; president of the Brazilian Society of Cardiovascula Surgery

Correspondence address:

Instituto Dante Pazzanese de Cardiologia

Av. Dante Pazzanese, 500

São Paulo - SP CEP 04012-180

E-mail: j.dinkhysen@uol.com.b 
Heart transplantation is the choice treatment for endstage congestive heart failure patients. After the first description by SHUMWAY et al. [1], several techniques have been suggested, among which is the total transplantation (bicaval/double-lung) which includes the complete excision of the right and left atria of the recipient (Rx) with orthotopic implantation of the donor (Dx) graft with the atria preserved.

\section{Donor-Rational}

In the process preceding the operation, the surgical team makes the final decision as to accept or not the donor organ, for which the recipient is analyzed in respect to the weight, occurrence of previous heart surgery, the transpulmonary gradient (TPG) [2] and the pulmonary vascular resistance index (PVRI) [3]. Thus, if the recipient ( $\mathrm{Rx}$ ) is being submitted to his first surgery and presents with low TPG and PVRI, the team may enjoy greater liberty in relation to acceptance of the donor organ. This enables greater tolerance in relation to the weight of the donor, which can be up to $10 \%$ less than the recipient and allows a greater margin of time of ischemia of the organ. However, if it is a re-intervention or the patient presents with higher indices, the logistics are more restrictive, times of ischemia greater than four hours and organs from donors with the same weight or heavier than the recipient are not acceptable.

Another important parameter is the age, as a young recipient should receive the organ from a young donor and older patients can receive organs from both young donors or donors with a similar age. When the recipient is young and has priority, an exception can be made and the patient can receive an organ from a donor of any age.

In the surgical room the donor is monitored, obtaining a continuous trace of the heart rhythm. The mean arterial pressure is obtained by means of cannulation of a peripheral artery and control of the arterial oxygen saturation by pulse oximetry. As there is no neurological function, there is no necessity to use anesthetic agents but pulmonary ventilation and appropriate circulation conditions should be maintained for good preservation of the organs.

In multiple organ donation, the harvesting sequence invariably commences with the heart, followed by the lungs, liver, kidney and corneas, always establishing a synchronism among all the harvesting teams.

Access to the heart is by longitudinal trans-sternal and longitudinal pericardiotomy median thoracotomy. Detailed inspection and palpation are made to guarantee the absence of fremitus and visible or palpable atheromatous plaques in the coronary artery system.

The ascending aorta and pulmonary artery (PA) are isolated, followed by dissection of the superior vena cava (SVC) and the inferior vena cava (IVC) from the pericardial reflection. In sequence, systemic heparization at a dose of $400 \mathrm{UI} / \mathrm{kg}$ of body weight is performed and a cardioplegic solution at $4^{\circ} \mathrm{C}$ is prepared. In cases where other organs are to be harvested, heparization is left until the respective pedicles are dissected.

The SVC is clamped proximal to the azygos vein, as is the IVC, which can be sectioned but powerful aspirators are required due to the necessity of a great amount of suction. After the heart is exsanguinated over 4 to 5 beats, the aorta is clamped at the most distal point possible and infusion of the cardioplegic solution is initiated through a puncture in the aorta.

The left chambers are decompressed by resection of the end of the left auricula or by partial sectioning of the right superior pulmonary artery. The right and left pulmonary veins (RPV and LPV) are then sectioned at their emergence in the pericardial cavity, leaving a small margin of tissue in the case of possible future harvest of the lungs (Figure 1).

(A)

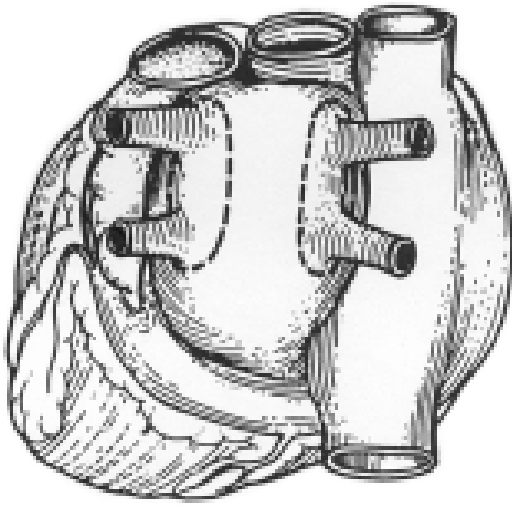

(B)

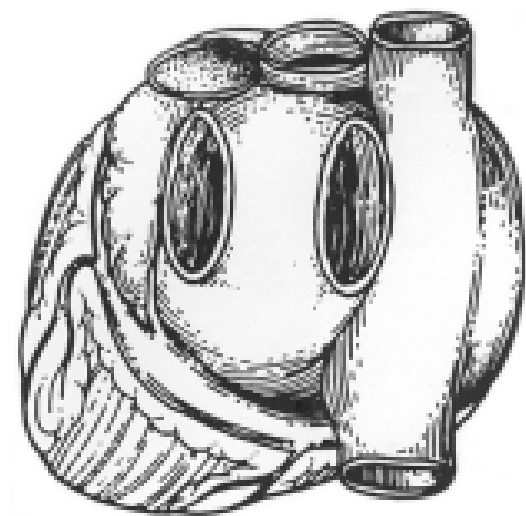

Fig. 1 - (A) Harvested donor heart with the stumps of the pulmonary veins [9].

(B) Double-lung/bicaval implantation with two openings, embodying the right and left pulmonary arteries [9]. 
The pulmonary artery is freed by sectioning its branches proximal to their origins. After finishing the infusion of the cardioplegic solution, the aorta is distally sectioned, followed by sectioning of the SVC, completing removal of the organ. This procedure enables the application of all the techniques of atrial, single-lung/bicaval and double-lung/bicaval implantation. Following this the graft is immersed in saline solution at $4{ }^{\circ} \mathrm{C}$

Transportation of the organ is achieved in a basin of saline solution at $4{ }^{\circ} \mathrm{C}$, to an adjacent room in the case of side-to-side transplantation. In the cases of harvesting at distance, the organ is packed in a cooled saline solution at $4{ }^{\circ} \mathrm{C}$, in appropriate sterile plastic bags, which are also covered with ice and placed in a thermal recipient [4].

\section{Recipient-Immunosuppression}

The pre-operative immunological induction is made only using methylpredisone $(500 \mathrm{mg} / \mathrm{EV})$ and another equal dose on entry to the recovery unit after the operation. In the first postoperative days methylpredisone is maintained at a dose of $10 \mathrm{mg} / \mathrm{kg} / \mathrm{day}$, with a progressive reduction over time. Cyclosporine is introduced when stabilization of the renal function is observed which generally occurs on about the second or third post-operative day, starting with low doses ( 50 to $100 \mathrm{mg} 4 \mathrm{x} /$ daily) with daily increases to a maximum of $4 \mathrm{mg}$ to $4.5 \mathrm{mg} / \mathrm{kg} /$ day. Micophenolate mofetil is administered from the second post-operative day $(50 \mathrm{mg} /$ day $)$ and should be progressively increased, taking into account the body weight [5]

In the operating theater, basic monitoring of the recipien includes continuous ECG by placing the electrodes on the dorsal surface, mean arterial pressure (MAP) by catheterization of the peripheral artery, central venous pressure (CVP) by the placing of a intracath in the SVC, pulse oximetry by the placement of a digital sensor temperature using an esophageal thermometer and urinary output by delayed vesicle probes. At anesthesia induction, the doses and the method of administration of the agents should be adjusted taking into account the low cardiac output and prolonged circulation time. In light of this, the patients in general, are sensitive to anesthetics and frequently require inotropic drugs, both during induction and in the maintenance of the anesthesia.

Fentanyl $(5 \mathrm{mcg} / \mathrm{kg})$ and etomidate $(0.3 \mathrm{mg} / \mathrm{kg})$ are commonly used in the induction of anesthesia, followed by neuromuscular blocks to facilitate endotracheal intubation, or vecuronium $(0.1 \mathrm{mg} / \mathrm{kg})$. Maintenance can be with sulfentanyl $(0.02 \mathrm{mcg} / \mathrm{kg} / \mathrm{min})$, midazolam in bolus depending on the necessity and vecuronium $(0.05 \mathrm{mg} / \mathrm{kg} / \mathrm{h})$. Inhalator anesthetics such as halogens in combination with nitrous oxide can also be utilized. Inotropic support and vasopressors should be administered with care until after starting cardiopulmonary bypass (CPB), aiming at an adequate organic and tissue perfusion. The volumetric, electrolytic disturbances, acid-base, and oxygenation corrections should be efficient and on time.

\section{Myocardial Protection}

Pharmacological cardioplegia attempts to eliminate the deleterious consequences of ischemia by creating a medium in which consumption by the tissue can be reduced. Thus, it should present as its main requisite protection of the heart by distribution of the pharmacological components throughout all the myocardium in a sufficient quantity to provide protection for the entire time of aortic clamping. The composition of the cardioplegic solution should have elements which enable cardiac arrest avoiding depletion of the energy, myocardial cooling thus diminishing the metabolic demand, providing substrate for aerobic and anaerobic metabolism, have buffering effect against acidosis, stabilize the membrane with specific drugs and avoid edema by hyper-osmolarity [6]. Among the strategies utilized, systemic hypothermia has been considered an important component, having as its main effect a reduction of the metabolism.

Myocardial preservation has been made with crystalloid cardioplegia at $4{ }^{\circ} \mathrm{C}$, composed of $500 \mathrm{~mL}$ of $5 \%$ glycine in saline solution augmented with $6 \mathrm{~mL}$ of $19.1 \%$ potassium chloride and $2 \mathrm{~mL}$ of $8.4 \%$ sodium bicarbonate. Cardioplegia should be performed at the moment of harvesting of the organ and during the implantation at every 40 minutes, associated with moderate systemic hypothermia with maintenance of the esophageal temperature at about $25^{\circ} \mathrm{C}$, thus requiring less re-warming of the graft. Aiming at reducing the time of anoxia, mainly in cases in which the ischemia time might be long, after the anastomoses of the pulmonary veins, the aorta can be anastomosed before the pulmonary artery and the vena cavas, thereby recovering the heartbeats.

\section{Bicaval double-lung Technique [7-10]}

Preparation for CPB is made using systemic heparization (400 UI $/ \mathrm{kg}$ of body weight) and cannulation of the ascending aorta or of the femoral artery and selective of the vena cavas, the most distally possible. On initiating the CPB, the esophageal temperature is reduced to about $25{ }^{\circ} \mathrm{C}$. It is necessary to direct attention to cases with previous heart operations. Of particular interest are those that underwent coronary artery bypass grafting, which, frequently, presented with adhesions that impeded the isolation of the native organ, making CPB and even cardiac arrest with deep hypothermia necessary. The aorta is clamped and opened for drainage of the heart. The aorta is dissected from the pulmonary artery and sectioned slightly above the level of the coronary ostia. The pulmonary artery is sectioned at the 
same position as the aorta. Removal of the native heart is performed by means of an incision initiated in the right atrioventricular sulcus which follows in the direction of the interatrial septum and around the left atrium, also accompanying the atrioventricular sulcus, leaving the atria anatomically whole.

The right atrium is then resected, maintaining a stump of 2 to $3 \mathrm{~cm}$ around each vena cava. Following this the left atrium is partially resected, maintaining the portion of atrial tissue round the pulmonary veins.

After this, the LA is totally removed, maintaining two stumps corresponding to the right and left pulmonary veins [9] (Figure 2).

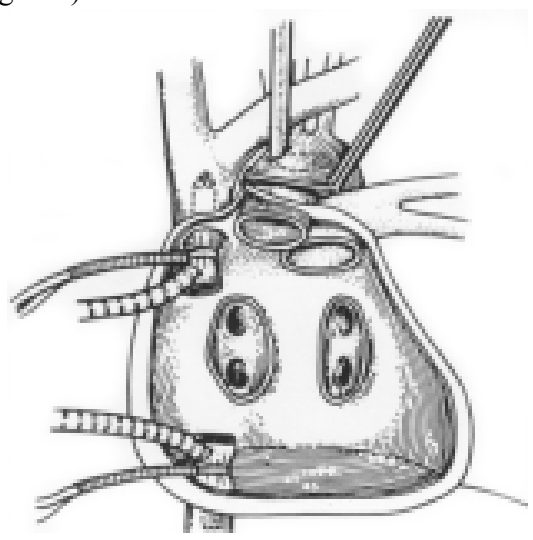

Fig. 2 -Recipient's organ removed with preservation of the right and left pulmonary veins respectively [9].

Implantation of the donor organ by anastomosing the stump of the left pulmonary vein with the corresponding orifice of the graft [9] (Figure 3).

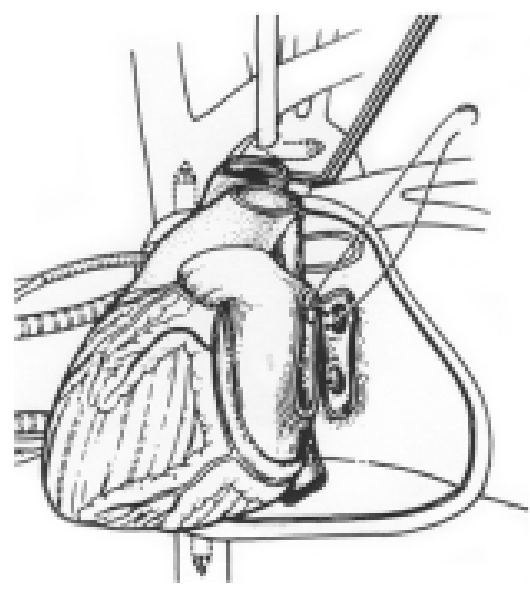

Fig. 3 - Anastomosis with the left pulmonary vein [9].
The return of the blood of the lung is completed by anastomosis of the stump of the right pulmonary vein with the corresponding orifice of the graft [9] (Figure 4).

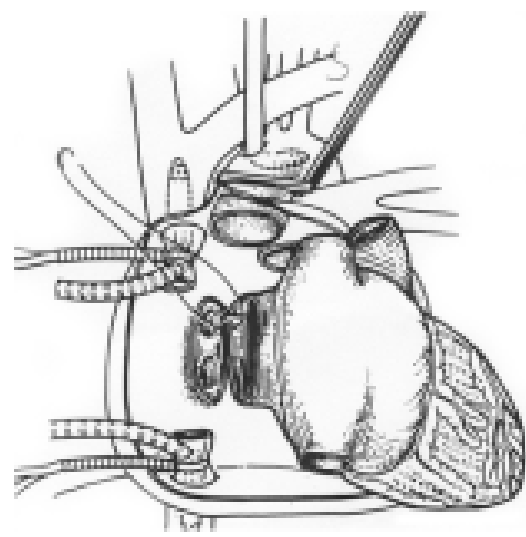

Fig. 4-Anastomosis with the right pulmonary vein [9].

Following this, the anastomoses of both vena cavas of the donor to the remaining stumps are performed, initiating with the inferior vena cava. The bicaval double-lung transplantation is completed with the anastomosis of the great arteries (pulmonary and aorta) [10] (Figures 5 and 6).

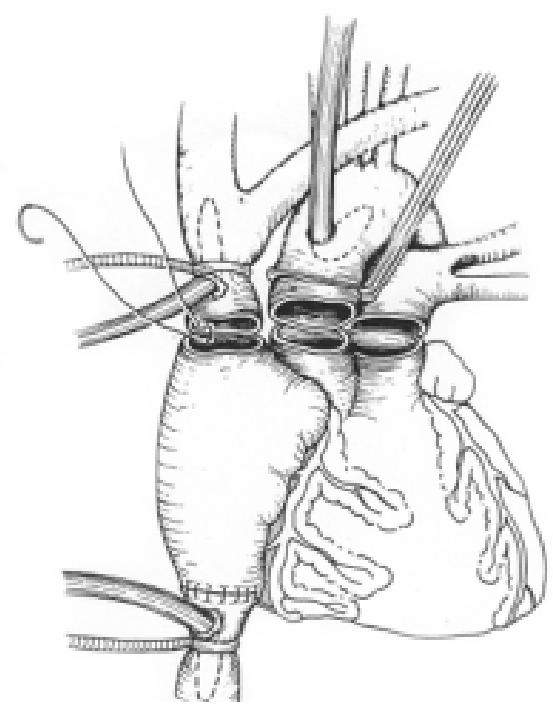

Fig. 5 - Anastomose with the superior vena cava [9]. 


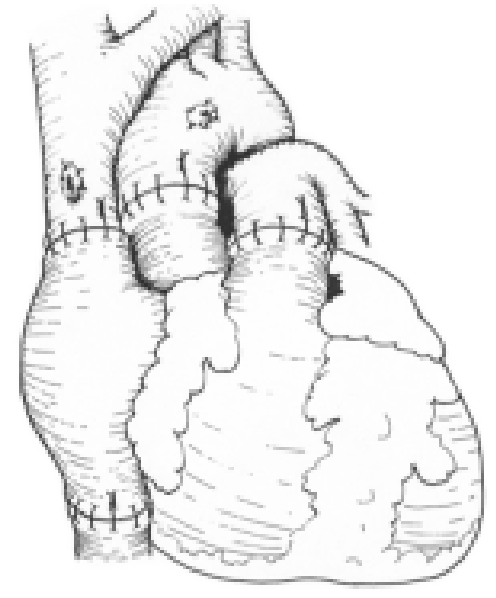

Fig. 6-Bicaval double-lung orthotopic Implantation [10].

With the aim of removing air from the left and righ chambers, the sutures of the SVC, PA, the aorta and the left auricle are not completed. Continue with the aortic declamping, obtaining recovery of the heartbeats and completing re-warming.

On being reperfused, the implanted heart presents with reduced contractility, bradycardia and, generally, junctiona rhythm reflecting not only the effects of the ischemia and hypothermia, but also the denervation of the graft. Inotropic drugs such as dopamine ( 3 to $10 \mathrm{mg} / \mathrm{kg}$ ), dobutamine ( 5 to $10 \mathrm{mg} / \mathrm{kg}$ ) or isoproterenol ( 0.005 to $0.05 \mathrm{mcg} / \mathrm{kg} / \mathrm{min}$ ) are employed, aiming at maintaining a heartbeat of between 100 to $110 \mathrm{bpm}$. When necessary, the maintenance of the heart rhythm is made by interim artificial stimulation by placing the lead of a temporary pacemaker on the myocardium.

After volumetric correction and stabilization of the arterial pressure, the cannulae of the aortic and vena caves are removed and the remaining sutures are completed, along with neutralization using heparin and protamine. The mediastinum is drained using a multi-perforated tubular drain, under the system of water seal, usually followed by the closure of the thoracotomy.

At the end of the operation, the patient is transferred to the ICU, with mechanical ventilation and all the cares necessary for the adequate continuation of the infusion of support drugs.
This technique was utilized for the first time in the Dante Pazzanese Institute of Cardiology in April 1997 and until now 113 patients were operated on with immediate mortality (30 days) of 15 patients (13.3\%), and late mortality of 17 (15.1\%)

\section{BIBLIOGRAPHIC REFERENCES}

1. Shumway NE, Lower RR, Stofer RC. Transplantation of the heart. Adv Surg 1966; 2: 265-84.

2. Kormos RL, Thompsonm M, Hardesty RL, Griffith BP Trento A, Urestiky BF et al. Utility of preoperative right heart catheterization data as a predictor of survival after heart transplantation. J Heart Transpl 1986; 5: 391

3. Addonizio LJ, Robbins RC, Reison DS, Drusin RE, Smith $\mathrm{CR}$, Reemtsa $\mathrm{K}$ et al. Transplantation in patients with high pulmonary vascular resistance. J Heart Transpl 1986; 5: 394.

4. Bocchi AE, Fiorelli A, Moreira LF, Bacal F. I Diretrizes da Sociedade Brasileira de Cardiologia para transplante cardíaco. Arq Bras Cardiol 1999; 73 (supl 8): 6-11.

5. Santos ES, Castro Neto J, Caruso PH. Tratamento cirúrgico da insuficiência cardíaca. In: Séries Monografias Dante Pazzanese vol. II; 2000. p.66.

6. Dinkhuysen JJ. Insuficiência cardíaca congestiva. Tratamento intervencionista. In: Timmernan A, ed. Urgências cardiovasculares. São Paulo: Sarvier; 1993. p. 250-64.

7. Banner NR, Khaghani A, Fitzgerald M, Mitchell AG, RadleySmith R, Yacoub MH. The expanding role of cardiac transplantation. In: Unger F, ed. Assisted circulation. $3^{\text {rd }}$ ed. Berlin: Springer; 1989. p. 448-67.

8. Yacoub M, Mankad P, Ledingham S. Donor procurement and surgical techniques for cardiac transplantation. Semin Thorac Cardiovasc Surg 1990; 2:153-61.

9reyfus G, Jebara V, Mihaileanu S, Carpentier AF. Total orthotopic heart transplantation: an alternative to the standard technique. Ann Thorac Surg 1991; 52:1181-4.

10. Blanche C, Valenza M, Czer LS, Barath P, Admon D, Harasty $\mathrm{D}$, et al. Ortothopic heart transplantation with bicaval and pulmonary venous anastomoses. Ann Thorac Surg 1994; 58:1505-9. 